\title{
Improved Performance of ZSI based UPFC for Enhanced Power flow in Interconnected System
}

\author{
Sunpreet Kaur Kharoud ${ }^{1}$ Parag Nijhawan ${ }^{2}$ \\ Department of Electrical and InstrumentationEngg. Thapar University, Patiala-147004, Punjab
}

\begin{abstract}
The FACTS (Flexible ac transmission systems) devices have all the capabilities to provide fast control of active and reactive power through a transmission line. The UPFC (unified powerflow controller) is a member of the FACTS family with very unique features. UPFC can control active and/or reactive power simultaneously or independently. This paper establishes the improved performance of ZSI (Z-Source inverter) based UPFC over VSI (Voltage source inverter) based UPFC for power flow improvement. The simulation models developed in MATLAB/SIMULINKhave been used to show the improvement in active and reactive power flows in an interconnected network.
\end{abstract}

Keywords: FACTS devices, Interconnected, Simulink, UPFC, Z-Source Inverter.

\section{Introduction}

Electrical energy is an essential ingredient for all-rounddevelopment of any country. It can be generated centrally inbulk and transmitted economically over long distances [1]. In today's highly complex and interconnected power systems, there is a great need to improve utilization factor of the existing infrastructure while still maintaining reliability and security. Reducing the effective reactance of lines by series compensation is a direct approach to increase transmission capability. However, a power transfer capability of long transmission line is limited by stability consideration [2]. Fast progression in the field of power electronics has already started to influence the power industry. This is one direct outcome of the concept of flexible ac transmission systems (FACTS) aspects, which has become feasible due to the improvement realized in powerelectronic devices[3].FACTS devices was first introduced in 1980s by Narain G.Hingorani [4]. In principle, the FACTS devices could provide fast control of active and reactive power through a transmission line. The unified power-flow controller (UPFC) is a member of the FACTS family with very attractive features. This device can independently or simultaneously control many parameter, since it has the combined properties of a static synchronous compensator (STATCOM) and static synchronous series compensator (SSSC) [3]. Among the FACTS devices, UPFC is regarded as one of the mostpowerful compensating device [5]. In this paper, the modelling and control of active and reactive power using Z-Source inverter based UPFC are simulated using MATLAB software. The simulation results are presented to show the effectiveness of ZSI in UPFC for improvement of power flow.

\section{Operating Principle Of Upfc}

The unified power flow controller consists of two switching converters. These converters are operated from a common dc link provided by a dc storage capacitor (Fig. 1).

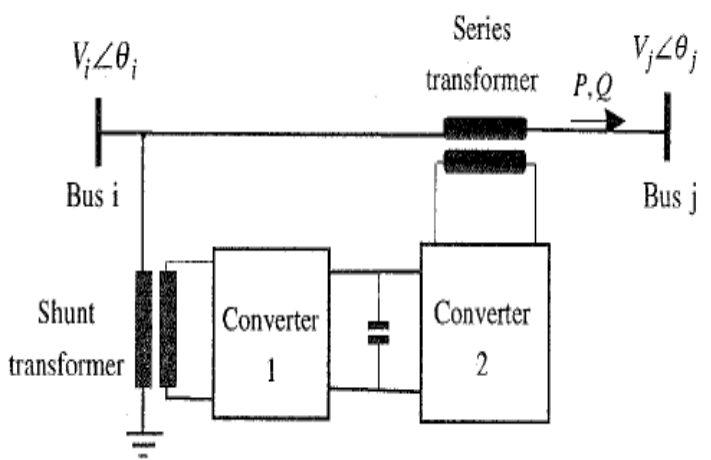

Fig. 1: Basic Circuit of UPFC

Converter 2 provides the main function of the UPFC by injecting an ac voltage with controllable magnitude and phase angle in series with the transmission line via a series transformer. The basic function of 
converter 1 is to supply or absorb the real power demand by converter 2 at the common dc link. It can also generate or absorb controllable reactive power and provide independent shunt reactive compensation for the line. Converter 2 supplies or absorbs locally the required reactive power and exchanges the active power as a result of the series injection voltage [6]. So, this inverter will exchange active and reactive power with the line. The reactive power is electronically provided by the series inverter, and the active power is transmitted to the dc terminals. The shunt inverter is operated in such a way as to demand this de terminal power (positive or negative) from the line keeping the voltage across the storage capacitor constant. dc V [7]

\section{Z-Source Inverter}

Z-source inverter (ZSI) can boost dc input voltage with no requirement of dc-dc boost converter or step up transformer, hence overcoming output voltage limitation of traditional voltage source inverter [8]. In addition to overcoming output voltage limitation it also lowers its cost[9].Z-source inverter has X-shaped impedance network on its DC side, which interfaces the source and inverter. The impedance network composed of split inductors and two capacitors. The supply can be DC voltage source or DC current source or AC source. Zsource inverter can be of current source type or voltage source type [8]. The main objective of static power converters is to produce an AC output waveform from a de power supply. The DC source can be a battery, diode rectifier, thyristor converter, fuel cell, PV cell, an inductor, a capacitor, or a combination of those [3]. Switches used in the converter can be a combination of switching devices and anti-parallel diodes as shown in Fig. 2 [10]

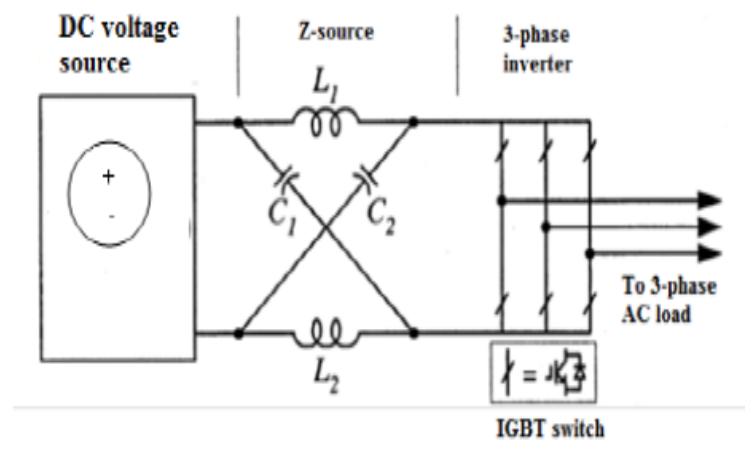

Fig.2: Z-Source Inverter

IV. Simulation Models

CASE I. Simulation Model without UPFC

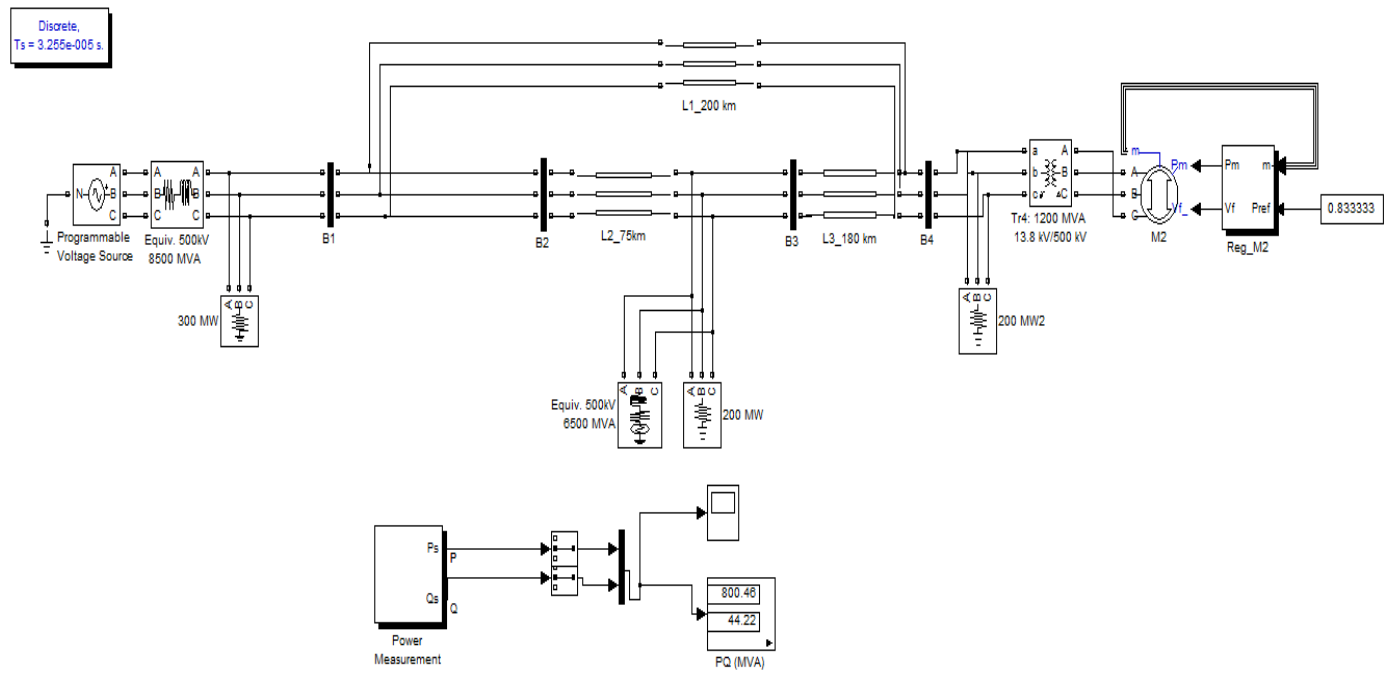

Fig. 3: Simulation Model without UPFC

Fig. 3 shows simulation model of interconnected power system without using UPFC. The Active power value is $800.46 \mathrm{MW}$ and Reactive power value is 44.22 MVAR as shown in Fig.4. 


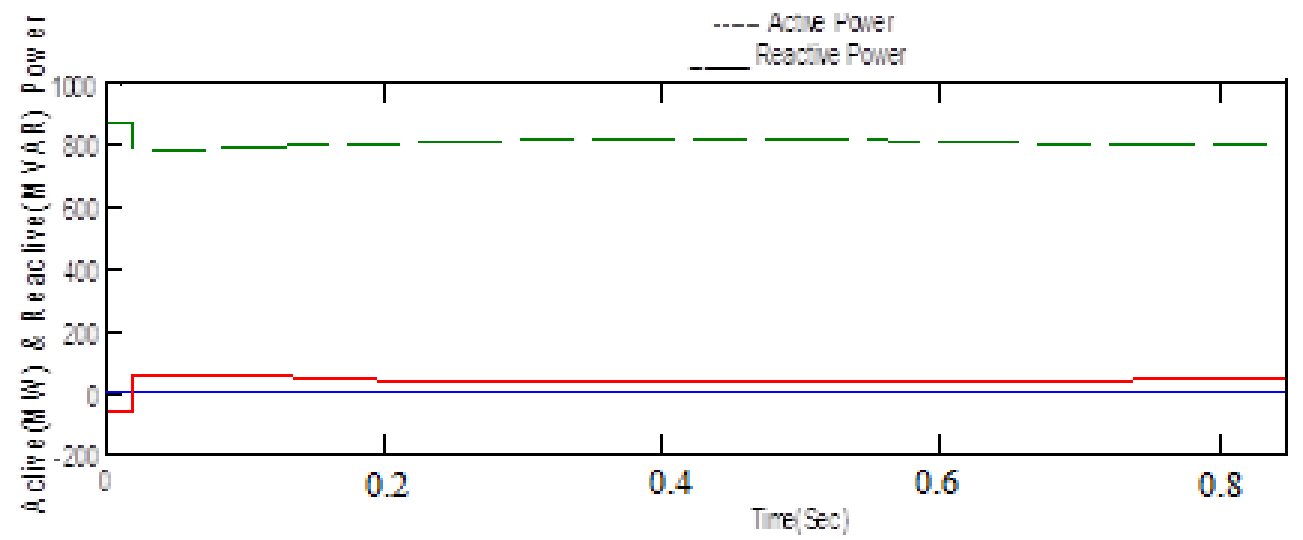

Fig. 4: Active and Reactive Power Flow without UPFC

\section{CASE II:Simulation Model with VSI based UPFC}

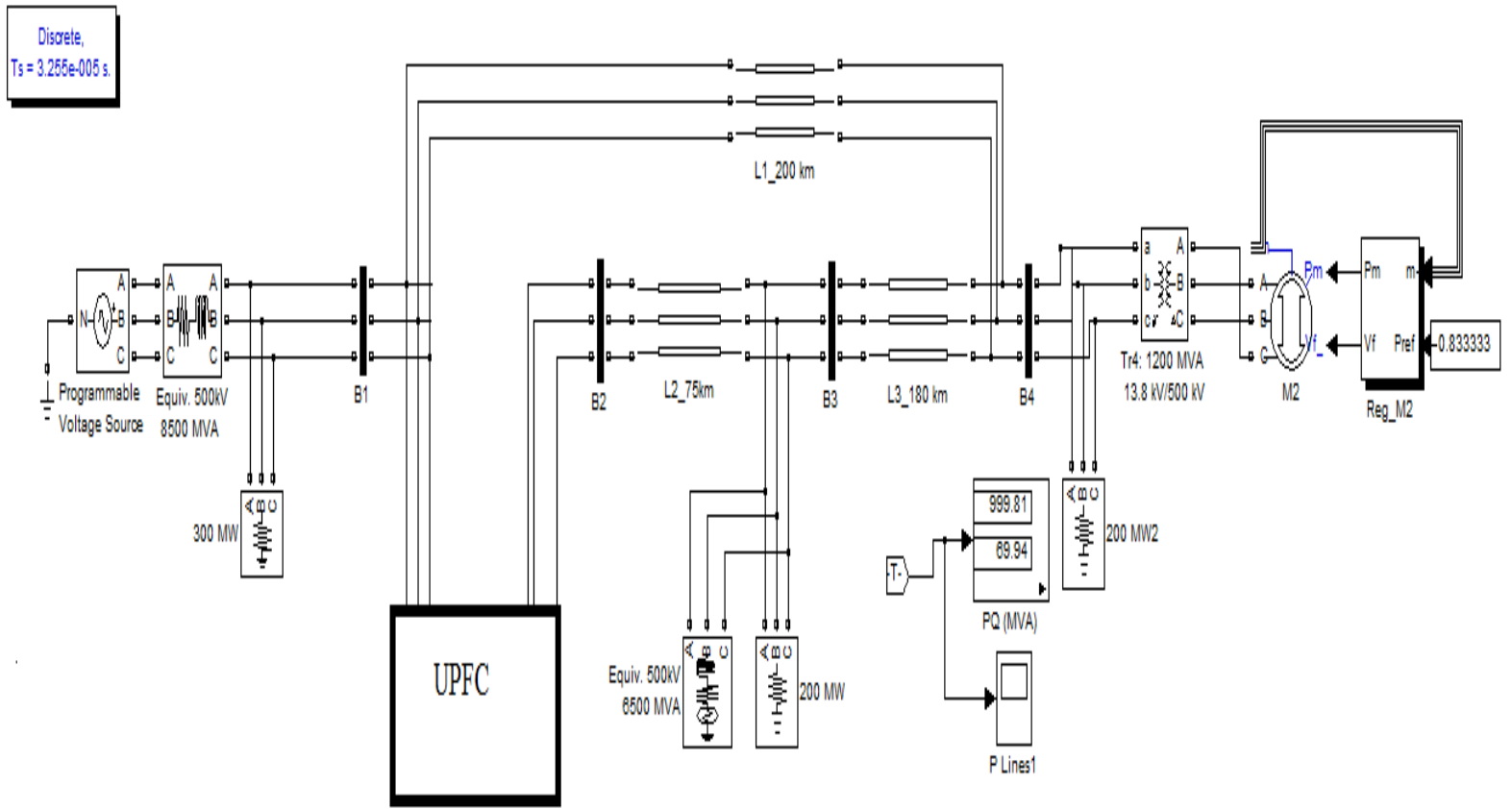

Fig.5: Simulation Model with VSI based UPFC

Fig. 5 shows simulation model of interconnected power system implementing VSI based UPFC. The Active power value is 999.81 MW and Reactive power value is 69.94 MVAR as shown in Fig. 6.

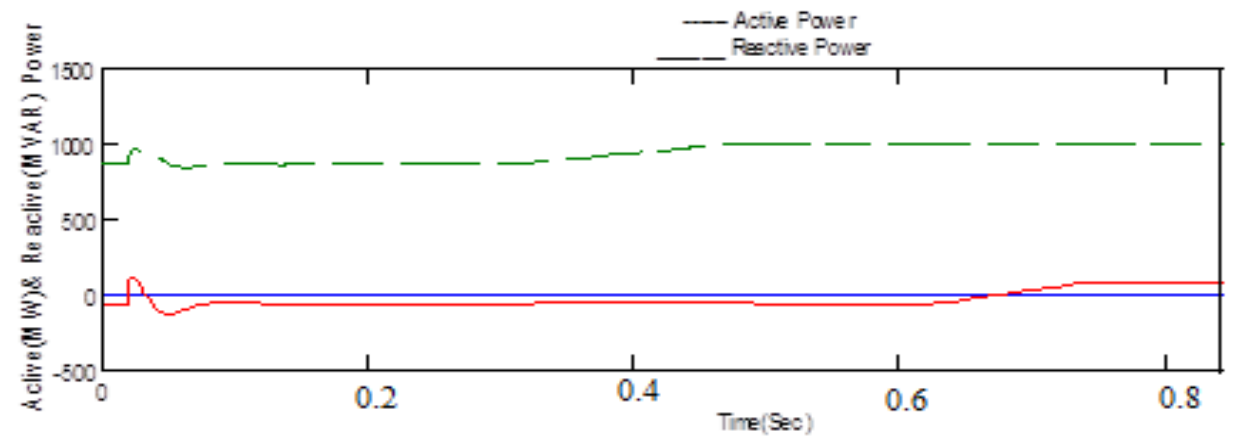

Fig. 6: Active and Reactive Power Flow with VSI based UPFC

Case III:Simulation Model with ZSI based UPFC 


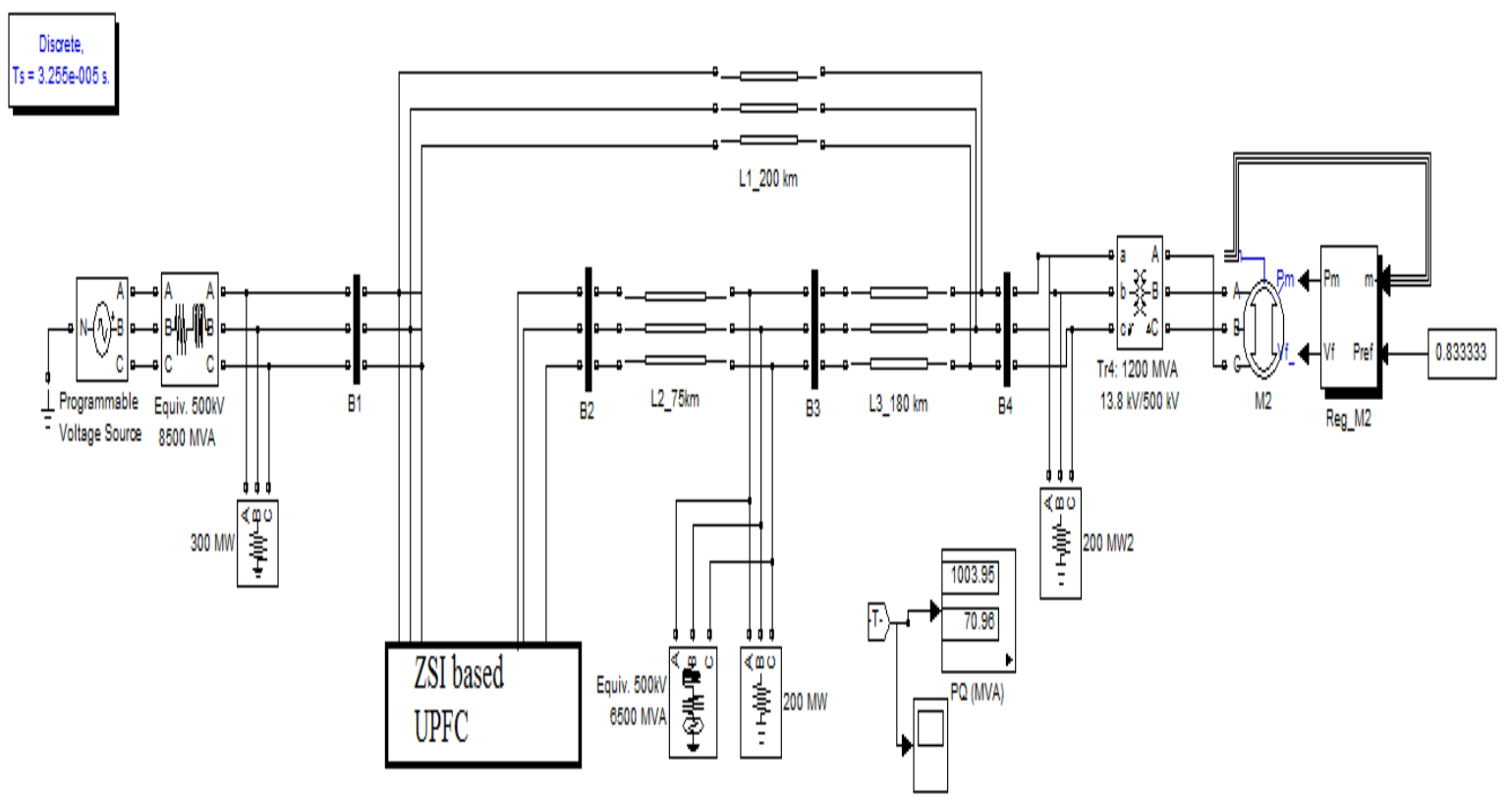

Fig. 7: Simulation Model with ZSI based UPFC

Fig. 7 shows simulation model of interconnected power system implementing VSI based UPFC. The Active power value is $1003.95 \mathrm{MW}$ and Reactive power value is 70.96 MVAR as shown in Fig. 8.

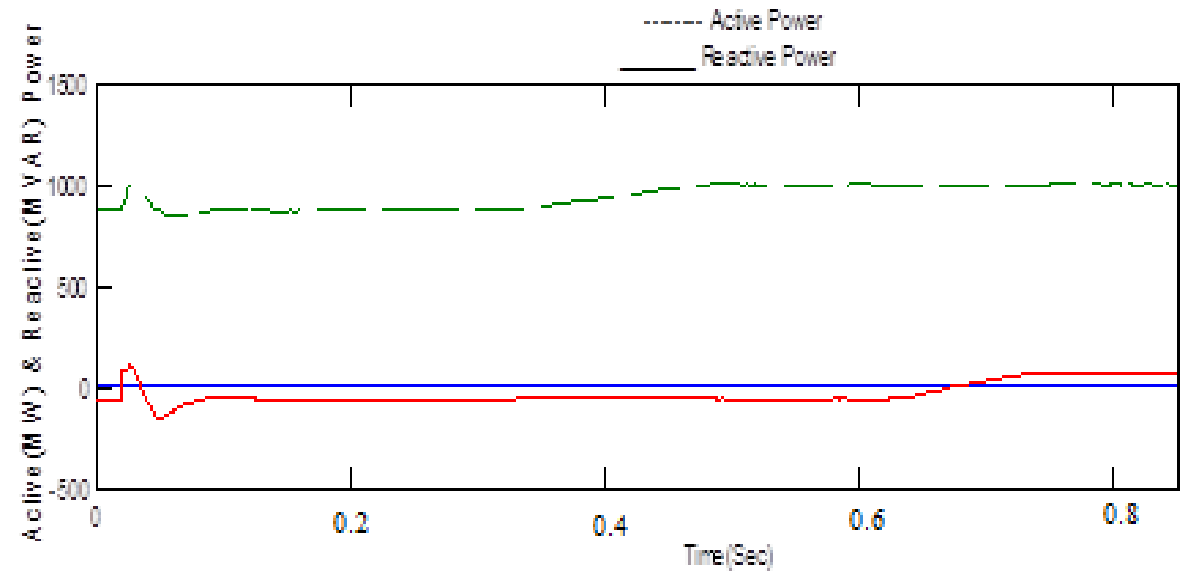

Fig. 8: Active and Reactive Power Flow with ZSI based UPFC

\section{Results}

The results obtained from the simulation models have been tabulated in Table-1. The active reactive power flows without UPFC in the interconnected network are observed to be $800.46 \mathrm{MW}$ and 44.22MVAR, respectively. The active reactive power flows with VSI based UPFC in the interconnected network are observed to be $999.81 \mathrm{MW}$ and 69.94MVAR, respectively. The active reactive power flows with ZSI based UPFC in the interconnected network are observed to be 1003.95MW and 70.96MVAR, respectively.

Table-1: Comparison of Active and Reactive Power flow

\begin{tabular}{|l|c|c|c|}
\hline \multicolumn{1}{|c|}{ Power Flow } & Without UPFC & With VSI Based UPFC & With ZSI Based UPFC \\
\hline Active Power(MW) & 800.46 & 999.81 & 1003.95 \\
\hline Reactive Power(MVAR) & 44.22 & 69.94 & 70.96 \\
\hline
\end{tabular}

\section{Conclusions}

Among the FACTS components UPFC is one of the most efficient devices which improve the Active and Reactive power flow in power system. The various simulation models i.e. interconnected power system without UPFC, With VSI based UPFC and ZSI based UPFC have been studied and results were analyzed. It is 
observed that the active and reactive power flow has been improved by 199.35 MW and 25.72 MVAR, respectively and with the use of VSI based UPFC in the power system. The active and reactive power has been further improved by 203.49 MW and 26.74 MVAR, respectively with the use of ZSI based UPFC. This clearly suggests that ZSI based UPFC is capable of utilizing the existing infrastructure more efficiently.

\section{References}

[1]. Garima Aggarwal, Lini Mathew and S Chatterji," Matlab/Simulink Based Simulation of an Hybrid Power Flow Controller" IEEE Fourth International Conference on Advanced Computing \& Communication Technologies, 2014, pp. 523-531.

[2]. Savider Malik, Lalit Dalal,'Implementation of UPFC for improvement of Power stability" IOSR Journal of Electrical and Electronics Engineering, Vol. 8, No. 6, pp. 44-50.

[3]. S. Muthukrishnan, Dr. A.Nirmalkumar and G. Murugananth, "Modeling and SimulationFive Level Inverter based UPFC System"International Journal of Computer Applications, Vol. 12, No.11, January 2011,pp.11-15.

[4]. N.F. Mailah, S.M. Bashi, N.Mariun and I.Aris,"Simulation of a three phase multi level Unified Power Flow Controller UPFC" Journal of Applied Sciences 2008,ISSN:1812-5654, pp.503-509.

[5]. Yao Shu-jun,Song Xiao-yan, Wang Yan, Yan Yu-xin, Yan Zhi,’Research on dynamic characteristics of Unified Power Flow Controller (UPFC) "IEEE 2011, pp.490-493.

[6]. M. Noroozian, L. Angquist, M. Ghandhari, G. Anderson, "Use of UPFC for optimalpower flow control"IEEE Transactions on Power Delivery, Vol. 12, No. 4, October 1997,pp.1629-1634.

[7]. Arup Ratan Bhowmik1, Champa Nandi2," Implementation of Unified Power Flow Controller (UPFC) for Power Quality Improvement in IEEE 14-Bus System","Int. J. Comp. Tech. Appl., Vol. 2, No. 6,Nov.-Dec. 2011, ISSN:2229-6093,pp. 1889-1896

[8]. B.Sharath Kumar and MD.Yaseen," Voltage Quality Improvement by using Facts Devices “ International Journal of Current Engineering and Technology ,ISSN:2277-4106,2013, pp.2094-2100.

[9]. B.Y. Husodo, M. Anwari, and S.M. Ayob Taufik," Analysis and Simulations of Z-Source Inverter Control Methods" IPEC 2010, pp.699-704.

[10]. Suresh L., G.R.S. Naga Kumar, M.V. Sudarsan \& K.Rajesh,” Simulation of Z-Source Inverter Using Maximum Boost Control PWM Technique" IJSS Vol.7 No.2, July-Dec. 2013, pp.49-59. 